\title{
GÊNERO E TRADUÇÃO: A ESCRITORA QUEBEQUENSE ANNE HÉBERT EM FOCO
}

\author{
Lílian Virgínia Porto* \\ Universidade Federal de Goiás
}

Ofir Bergemann de Aguiar** Universidade Federal de Goiás

\begin{abstract}
Resumo: Este trabalho tem por objetivo mostrar a importância da escritora quebequense Anne Hébert (1916-2000) no desencadeamento de uma nova prática de tradução no Canadá, a tradução feminista, que tem como maiores representantes Barbara Godard, Susanne de Lotbinière-Harwood, Luise von Flotow e Sherry Simon. Destaca-se a discussão, entre Hébert e Frank Scott, em torno da tradução do poema hebertiano Le tombeau des rois, realizada por Scott. São mencionados os temas recorrentes da
\end{abstract}

\footnotetext{
* Mestrado (2006) em Literaturas Francesa e Francófonas pela University of Saskatchewan, Canadá. Doutorado (2012) em Letras e Linguística pela Universidade Federal de Goiás. É professora do Departamento de Línguas e Literaturas Estrangeiras (Área de Francês) da Faculdade de Letras da Universidade Federal de Goiás (UFG). Coordenadora do Núcleo de Estudos Canadenses (NEC) na mesma universidade. Goiânia, Goiás, Brasil. E-mail: lilianportoufg@gmail.com

** Possui graduação (1979) em Relações Internacionais pela Universidade de Brasília (UnB), mestrado (1991) e doutorado (1997) em Letras pela Universidade Estadual Paulista Júlio de Mesquita Filho (UNESP). Foi Oficial de Chancelaria do Ministério das Relações Exteriores de 1977 a 1987. É professora associada IV da Universidade Federal de Goiás (UFG), onde atua desde 1991. Coordenadora de Assuntos Internacionais da UFG desde 2006. Goiânia, Goiás, Brasil. E-mail: ofirbergemann.ufg@gmail.com
} 
obra de Hébert que, a partir dos anos de 1990, passou a ser lida pelo viés feminista: relações familiares conflituosas, revolta e violência das personagens, clausura interior do ser humano e seu desejo de liberação, ressaltando-se o tratamento dado ao universo feminino. São comentados, ainda, problemas de gênero envolvendo duas traduções do romance hebertiano Kamouraska.

Palavras-chave: Gênero e tradução. Anne Hébert. Tradução feminista.

\title{
GENDER AND TRANSLATION: FOCUS ON THE QUÉ- BÉCOIS WRITER ANNE HÉBERT
}

\begin{abstract}
The objective of this paper is to demonstrate the importance of the Québécois writer Anne Hébert (1916-2000) to the development of a new translation practice in Canada, the feminist translation, which has as prominent contributors Barbara Godard, Susanne de LotbinièreHarwood, Luise von Flotow, and Sherry Simon. In this context, it is of significance the conversation between Hébert and Frank Scott about the translation of her poem Le tombeau des rois, by Scott. The recurrent themes in Anne Hébert works that after the 1990ths are read in a feminist perspective are mentioned, namely: conflicting family relationships, anger and violence of the characters, interior imprisonment of the human being, and his desires of liberation, emphasizing the treatment of the female universe. The gender issues involving two translations of the hebertian novel Kamouraska are also discussed.
\end{abstract}

Keywords: Gender and translation. Anne Hébert. Feminist translation.

A escritora quebequense Anne Hébert (1916-2000) tem importância capital para a paisagem literária do Canadá. Além de ser célebre no mundo francófono, é uma das autoras mais comentadas pela crítica anglo-canadense e seus textos são os mais traduzidos para o inglês, ao lado de escritoras como Gabrielle Roy e Marie-Claire Blais (GODARD, 2002, p. 66).

O interesse pela obra hebertiana em seu próprio país e fora dele é bastante expressivo. No âmbito canadense, citamos, entre outras, a pesquisa coordenada por Nathalie Watteyne: Édition critique des œuvres d'Anne Hébert (CRSH 2006-2009 ; 2009-2013). ${ }^{1}$ Cabe des- 
tacar, também, a fundação do Centre Anne Hébert, que tem por principal objetivo motivar a pesquisa e divulgar os trabalhos realizados sobre esta autora e também promover a literatura escrita por mulheres. Este centro publica anualmente a revista Cahiers Anne Hébert, um periódico de referência para os estudiosos da obra hebertiana. ${ }^{2}$

O prestígio internacional de Anne Hébert pode ser observado, sobretudo, pela ampla recepção de sua obra ao redor do mundo. A maior parte de seus livros foi traduzida para diferentes línguas como chinês, neerlandês, sueco, polonês, grego, espanhol, inglês, português. À parte os numerosos textos críticos, várias teses e dissertações foram dedicadas aos seus romances, à sua poesia, ao seu teatro, aos seus contos e aos filmes adaptados de seus romances, conforme comprova bibliografia organizada por Watteyne (2008, p. 7), que totaliza 3.060 referências.

Poeta, dramaturga, contista, romancista, Anne Hébert praticou diferentes gêneros literários com igual desenvoltura. Sua obra inspira leituras em diferentes abordagens, não sendo circunscrita a algum grupo ou corrente literária, resistindo a interpretações unívocas (PATERSON, 1985, p. 13).

Desse modo, não se permitindo ser aprisionada por nenhuma corrente ou movimento literário, a escritura de Anne Hébert tem sido associada à violência das personagens e à revolta contra comportamentos submissos (GAUVIN; MIRON, 1998, p. 264). Chamam a atenção em sua obra, ainda, as relações familiares que não são nada tranquilas como desejava a ideologia conservadora durante a Grande Noirceur [Grande Escuridão] - período em que a evolução cultural e social do Quebec foi abafada (1944-1959) e em que Hébert publicou seus primeiros textos.

Com efeito, entre as temáticas recorrentes da obra de Anne Hébert, destacamos as relações familiares conflituosas, quase sempre motivadas por uma condição social opressora. Isso se reflete no modo como as famílias constroem essa relação, deixando o indivíduo sufocado (ex. Le Torrent, Les chambres de bois, Le temps sauvage). Sobressaem-se também os temas da revolta e da violência 
das personagens (Le Torrent, Les fous de Bassan) e, particularmente, das femininas (Kamouraska). Ressalta-se, ainda, a trajetória de uma personagem que procura definir sua identidade cultural e individual, como é o caso de Flora Fontanges (Le premier jardin).

A personagem hebertiana possui um sentimento de exílio existencial e/ou social (BISHOP, 1993) sendo, quase sempre, atormentada por seu passado. De fato, tempo e identidade são aspectos que atingem profundamente a personagem de Hébert (MARCHEIX, 2005). É uma personagem que está em busca de si mesma, uma busca que também se delineia na narrativa (LINTVELT, 1996) e, mais particularmente, nos planos temporais múltiplos que costumam revelar a identidade cindida entre o aqui e o acolá. São, enfim, a clausura interior do ser humano e seu desejo de liberação, os temas basilares da obra desta escritora.

\section{Hébert pelo viés feminista}

Esses temas - a clausura, a alienação e a violência - estão entre os mais examinados na obra de Anne Hébert durante os anos de 1980, mas, a partir dos anos de 1990, tornaram-se recorrentes os estudos com abordagens linguísticas e feministas (WATTEYNE, 2008, p. 9). A publicação de Anne Hébert en revue, sob a direção de Paterson e Saint-Martin (2006), testemunha a riqueza e a diversidade de pontos de vista críticos - leituras temáticas, narratológicas, intertextuais, feministas - nas análises da obra da escritora em pauta. Esta coletânea reúne textos que vão de 1975 a 2002, apresentando-nos uma constante da obra de Hébert que a crítica não esgotou: a dualidade de sua obra, que oscila entre pólos opostos: "catividade e liberação, bem e mal, dia e noite, passado e presente, vida e morte" ${ }^{3}$ (PATERSON; SAINT-MARTIN, 2006, p. 7). Tais tensões continuam a despertar o interesse de estudiosos.

À parte as temáticas supracitadas e os aspectos ditos universais da obra hebertiana - tais como a incomunicabilidade dos seres e 
as angústias existenciais do indivíduo - que lhe valeram reconhecimento internacional, destaca-se, na obra da autora, o tratamento do universo feminino. Em Anne Hébert, encontramos um leque de personagens femininas de todas as idades e classes sociais, mulheres e meninas que não parecem satisfeitas com o destino que lhes reserva uma sociedade baseada em princípios tradicionais que as excluem de toda forma de acesso à cultura e à liberdade de decisão. Por isso, a obra desta escritora é apontada por Lori Saint-Martin (1989, p. 185) como imprescindível para se estudar a representação da mulher na literatura quebequense.

Inserida num novo contexto social - final dos anos oitenta e desenrolar dos anos noventa, que assinala o rápido desenvolvimento dos estudos feministas no Quebec - a obra de Anne Hébert suscita uma profusão de leituras à luz dessa nova configuração no plano literário quebequense (SAINT-MARTIN, 1989; BISHOP, 1993; ANCRENAT, 1999). Depreendem-se dessas leituras a riqueza e a complexidade de uma obra que, ao ser examinada pelo viés feminista, coloca em evidência um texto que denuncia uma condição feminina oprimida por meio da força das palavras e de sua poesia, levando o leitor a sentir a dor e o prazer. Não se vê explicitada nessa obra, no entanto, uma reivindicação dos direitos de mulheres e homens, o que a vincularia ao que se convencionou chamar de literatura engajada.

Ocorre que, ao explorar o universo feminino, Hébert chama a atenção para problemas ligados à construção social do masculino e do feminino, no sentido de observar o que um dado contexto social e cultural destina aos homens e às mulheres. Percebemos, em seus textos, por exemplo, no romance Les fous de Bassan (HÉBERT, 1992), o questionamento dos papéis que homens e mulheres assumem na sociedade e o modo pelo qual se estabelece a relação de poder entre ambos. Cumpre salientar que a vertente feminista vem despertando interesse cada vez maior por parte dos pesquisadores da obra de Anne Hébert. A publicação do volume 08 do Cahiers Anne Hébert, cujo título é Féminin/masculin dans l'oeuvre d'Anne Hébert (BOISCLAIR; SAINT-MARTIN, 2008), comprova esse interesse. 
Não é só no movimento feminista literário quebequense, todavia, que Hébert e sua obra têm papel significativo. Ao discutir um problema de tradução do seu poema Le tombeau des rois (1953), Hébert suscitou, pela primeira vez no Canadá, uma discussão sobre gênero em tradução que acabou por desembocar em uma nova prática de tradução.

\section{Hébert e a tradução feminista no Canadá}

A pesquisa em tradução e gênero no Canadá torna-se visível a partir dos anos oitenta (VON FLOTOW, 2006). Nesse período, são organizados encontros, conferências, colóquios e há a fundação de editoras feministas (The Women's Press, Edições de Pleine Lune, Edições du remue-ménage). Há ainda comentários da academia e traduções que trazem, em prefácios e introduções, comentários do tradutor, que discute os aspectos subjetivos do seu trabalho.

Todas essas atividades foram contribuindo para a constituição de um novo campo de pesquisa. Mas foi precisamente em 1986 durante um evento organizado pela American Literary Translator's Association, que contou com a participação de Sherry Simon, Suzanne de Lotbinnière-Harwood, Barbara Godard e Kathy Mezei, que houve uma tomada de consciência sobre o surgimento de uma nova prática de tradução no Canadá. Simon, editora dos anais deste evento, explica: "Foi somente ao final de nossas discussões que percebemos que algo novo havia surgido. Nascia uma prática que poderíamos chamar de tradução feminista canadense" ${ }^{4}$ (1996, p. vii, grifo nosso). Importa observar que, durante esse evento, as falas de Godard e Lotbinière-Harwood, foram, segundo von Flotow, recebidas com certa hostilidade por alguns tradutores literários presentes, porque muitos deles acreditavam que tradução "é um evento apolítico, e o tradutor um condutor inocente" 5 (2006, p.18).

Ressalte-se que essa nova prática de tradução que se formava no contexto canadense, impulsionada pela demanda de tradução de 
textos feministas quebequenses para o Canadá inglês, caracterizou-se não apenas pela tradução de textos para um mercado em demanda. Reflexões teóricas contribuíram também para a definição dessa área de estudo, destacando-se o trabalho de quatro pesquisadoras canadenses: Barbara Godard, Susanne de Lotbinière-Harwood, Luise von Flotow e Sherry Simon.

Cabe então, nesse contexto, mencionar a tradução do poema hebertiano Le tombeau des rois, realizada por Frank Scott que, conforme assinalamos, despertou, pela primeira vez no Canadá, uma discussão sobre gênero em tradução. Esse fato é significativo e suscitou o interesse subsequente por parte da crítica feminista em torno da obra de Anne Hébert. É pertinente lembrar que foi Hébert quem chamou a atenção de seu tradutor para um aspecto que ocultava o feminino na tradução desse poema. Lê-se no original:

$[\ldots]$

(En quel songe

Cette enfant fut-elle liée par la cheville

Pareille à une esclave fascinée ?)

(HÉBERT; SCOTT, 1970, p. 30)

Na primeira tradução de Scott lê-se:

(In what dream

Was this child tied by the ankle

Like a fascinated slave?)

(HÉBERT; SCOTT, 1970, p. 31)

Observamos que a tradução não assinala que a criança é uma menina, o que é indicado em francês por cette enfant, esclave fanscinée, liée. Lembramos que o e constitui a marca do feminino quando colocado no final de adjetivos (fascinée $=$ fascinada) e do particípio passado dos verbos (liée = ligada), e que cette é o adjetivo demonstrativo referente ao feminino, correspondente a "esta" ou "essa".

O poema refere-se, portanto, a uma menina e reforça uma leitura emblematizada por alguns críticos, como Kathy Mezei (1986, 
p. 141), de que se trata de um estupro ritual. O que está em cena é uma jovem que desce ao túmulo dos reis e é violentada pela mão pesada da morte remetendo a um passado patriarcal. Transcrevemos este excerto do poema, na tradução de Hanciau (2009, p. 62-63): "Ávidos da fonte fraterna do mal em mim; / Eles me deitam e me bebem; / Sete vezes, conheço o torno dos ossos; / E a mão seca

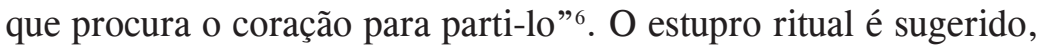
sobretudo, por "Eles me deitam e me bebem".

Após a intervenção de Anne Hébert, Scott resolveu o problema de gênero no trecho citado acima substituindo the ankle (o tornozelo) por her ankle (o tornozelo dela). Cabe mencionar que este exemplo foi evocado por vários críticos e toda essa discussão entre Hébert e Scott em torno da tradução do poema mencionado (incluindo a versão original em francês e a tradução de Scott para o inglês) foi publicada em Dialogue sur la traduction (HÉBERT; SCOTT, 1970).

Godard (1984) e Mezei (1986) assinalam esse momento capital no diálogo dos poetas para inserir uma nova problemática no âmbito da tradutologia, a da diferença sexual. Em outro texto, Godard igualmente explica que as discussões sobre a diferença sexual em tradução foram primeiramente suscitadas no Canadá, no contexto da tradução do poema de Anne Hébert, Le tombeau des rois de 1953: "O que começou como um diálogo sobre tradução entre os poetas Hébert e Scott tornou-se, em seguida, um diálogo entre feministas a propósito das assimetrias de poder em torno da diferença linguística e sexual" (GODARD, 2009, p. 139).

Mezei observa, contudo, que o acesso a essa discussão e à tradução de Scott nem sempre influenciou o trabalho de outros tradutores desse poema. A resposta de muitos para o problema em estudo assinala uma ausência de sensibilidade em relação à presença da mulher no poema, insensibilidade para o significado da diferença sexual e, ainda, para as diferentes manifestações de gênero nas línguas inglesa e francesa (1986, p. 141).

Exemplos de discussão como essa, que originou o texto Dialogue sur la traduction, são abundantes e servem para ilustrar a cha- 
mada "tradução feminista". Lotbinière-Harwood (1991, p. 107108), por exemplo, comenta um trabalho de tradução que ela fez. Trata-se de um livro de Jovette Marchessault intitulado La terre est trop courte, Violette Leduc, que inclui citações da obra de Leduc, La bâtarde, que já havia sido traduzida por Derek Coltman. Harwood não quis usar o texto de Coltman e propôs sua própria versão para a frase abaixo transcrita, o que foi aprovado por Leduc.

Vejamos a frase retirada do livro La bâtarde de Violette Leduc, de 1964: "Je suis née brisée. Je suis le malheur d'une autre. Une bâtarde, quoi !" Na versão do tradutor Derek Coltman, publicada em 1965, lemos: "I was born broken. I am someone else's misfortune. A bastard!"

O leitor de Coltman não toma conhecimento de que se trata da infelicidade de uma mulher, uma vez que o tradutor optou por someone else, que corresponde a "alguém". No texto em francês isso é explicitado pelo pronome indefinido feminino une em: le malheur d'une autre. A tradução proposta por Harwood foi: I was born broken. I am another woman's sorrow, a bastard, em que ela inclui o vocábulo woman (mulher).

Outro exemplo pode ser observado no artigo de von Flottow (1991, p. 75), em que ela menciona a tradução da seguinte frase, da obra L'Euguélionne, de Louky Bersiannik, que remete ao aborto: "Le ou la coupable doit être punie". Howard Scott para dar ênfase ao fato de normalmente ser a mulher a considerada culpada pelo aborto, o que é ressaltado no texto francês que traz a marca do feminino no particípio passado punie (punida), propõe a seguinte tradução inglesa : "The guilty one must be punished, whether she is a man or a woman". Nesse caso, a indicação da culpa da mulher é explicitada pela inclusão do pronome pessoal feminino she, correspondente a "ela": seja "ela" um homem ou uma mulher.

Cumpre-nos salientar que a tradução feminista se utiliza de técnicas intervencionistas para operar a reescrita de um texto, porém, conforme assinala Godard: "A intervenção feminista na teoria e na prática da tradução não se limita [à] análise de lacunas na tradução de textos de mulheres por tradutores masculinos, mas se debruça 
sobre toda a problemática da autoria textual e da transmissão do saber" (GODARD, 2009, p. 139). E ainda, conforme observa Sherry Simon, a tradução feminista reformula a questão da fidelidade do tradutor que não é mais direcionada para o autor nem para o leitor, mas para o projeto de escrita, um projeto em que ambos, escritor e tradutor participam (1996, p. 2).

Fazem parte das estratégias feministas de tradução a não observância de regras gramaticais e sintáticas, assim como a fragmentação da linguagem e o desmembramento de palavras com o objetivo de explicitar o que está implícito (VON FLOTOW, 1991; SIMON, 1996). A tradução feminista não se preocupa com imparcialidade, o que pretende ao contrário é revelar como a língua-alvo não é neutra (IRIGARAY, 1985). Conforme menciona Aguiar, esta interferência explícita no texto que está sendo traduzido é "vista, por alguns, como um ato ético, pois seu trabalho é discutido nos prefácios e nas notas de pé de página que acompanham as traduções" (2003, p. 16).

As discussões elaboradas por tradutoras feministas em prefácios e notas de rodapé travam, na maior parte das vezes, um diálogo com outras tradutoras feministas. Há casos em que o tradutor agradece a outros acadêmicos ou tradutores, como o faz Barbara Godard, mostrando a importância de um grupo pequeno e próximo com quem trabalha, discute, troca ideias e que o apoia (VON FLOTOW, 2006, p. 16-17). Essa prática enfatiza que o tradutor não é um filtro, um mero transmissor de conteúdo de uma língua para outra, porque acredita-se que tradução é, antes de mais nada, uma leitura.

Esse diálogo revela como a discussão entre gênero e tradução contribui para mostrar a complexidade do processo tradutório, pois este envolve questões de diferentes ordens, políticas, linguísticas, culturais, entre outras. Com isso, constata-se que a tradução "produz conhecimento e significado e não apenas repetições" (VON FLOTOW, 2007, p. 95) ${ }^{7}$, conforme ilustram, entre outros, os comentários, acima mencionados, em torno da tradução para o inglês do poema Le tombeau des rois. 


\section{Problemas de gênero em duas traduções do romance heber- tiano Kamouraska}

O poema Le tombeau des rois não foi o único que suscitou discussão sobre um problema relacionado ao gênero em tradução de obra de Anne Hébert. A tradução do romance Kamouraska (HÉBERT, 1970), realizada por Norman Shapiro e publicada nos Estados Unidos em 1973 (HÉBERT, 1973), também chamou a atenção da crítica. Foi Shirley Fortier (2001) quem observou que a protagonista Elisabeth d'Aulnières não é a mesma na obra que foi apresentada para o público daquele país. Afirma que as escolhas do tradutor camuflaram as características feministas do texto de partida, passando a imagem de uma Elisabeth menos decidida e menos inconformada com sua situação de clausura doméstica.

Para ilustrar este aspecto apontado pelo trabalho mencionado, vejamos dois exemplos. Para a declaração de Elisabeth em Hébert: "Amour, amour, je te mords, je te bas, je te tue" (K, p. 9) ${ }^{8}$, lê-se em Shapiro: "My love, my love. Let me bit you, beat you, kill you". $(\mathrm{T}, \text { p. 3) })^{9}$. Ora, Elisabeth não é uma mulher que implora ou pede permissão. Neste caso, o let (deixe) torna a ação menos afirmativa e não testemunha o controle físico atribuído à mulher.

Vê-se, no exemplo a seguir, que o tradutor insere um novo elemento, incluindo uma vez mais um pedido de permissão. A personagem no texto de Hébert diz o seguinte: "Docteur Nelson, je vous aime farouchement jusqu'à désirer franchir avec vous les sources de votre enfance" (K, p. 122) ${ }^{10}$. Na tradução: "I will love you wildly, madly, Doctor Nelson. Please, let me go with you [...] back to your childhood" (T. p. 117) ${ }^{11}$. A inclusão de Please, let me [Por favor, deixe-me] atenua a personalidade forte e decidida de Elisabeth.

Vale ressaltar que esses exemplos são apenas ilustrativos de uma problemática mais ampla, porque é o conjunto de diferentes escolhas que desvirtuou a atmosfera bem como a personalidade da personagem. Essas escolhas refletiram-se na recepção crítica da 
obra em 1973. Fortier menciona títulos de artigos e de resenhas do romance que fazem uma leitura de Kamouraska que aproxima este texto de Hébert do romantismo inglês (2001, p. 8).

Na tradução desse romance no Brasil, realizada por Leônidas Gontijo de Carvalho com o título de A Máscara da Inocência (HÉBERT, 1972), também são observadas atenuações de marcas feministas da obra de Hébert. Antes, porém, de introduzi-las, importa esclarecer que entendemos "feminismo", no contexto dessas análises, de maneira ampla, conforme Rita Felski, (1989, p.14): "todos aqueles textos que revelam uma consciência crítica da posição subordinada das mulheres e da categoria gênero como problemática, independentemente do modo como isso é enunciado" 12 .

Observemos o fragmento a seguir, no original e na versão de Carvalho, que apresenta a protagonista no ventre de sua mãe, Marie-Louise. Esta se tornara viúva aos seis meses de gravidez e desmaia ao ver o caixão do marido sendo levado de casa. Elisabeth se desespera e faz de tudo para acordá-la de um desmaio que poderia ser fatal para as duas:

Le cercueil de mon jeune père quitte la maison. Ma mère s'évanouit. Et moi, bien enfermée à double tour, je lui donne des coups de pied dans le foie. Pour la réveiller. Je me démène comme un cabri. Nous pourrions en mourir toutes les deux, ma mère et moi, d'un évanouissement aussi terrible et prolongé.

Quelle petite fille malfaisante !

Est-ce là la première voix du monde qui parvient à mes oreilles?

(K, p. 51).

O caixão de meu jovem pai que deixa a casa. Minha mãe desmaia. E eu, tão bem encarcerada, dou-lhe pontapés no fígado para despertá-la. Agito-me violentamente como um cabrito. Nós duas, mamãe e eu, poderíamos morrer de um 
desmaio assim terrível e prolongado.

- Que criança daninha!

É essa a primeira voz do mundo que me chega aos ouvidos?

(TK, p.47-48).

Observe-se que a primeira frase materna que Elisabeth ouve não é expressão de carinho, mas de descontentamento e incômodo: Quelle petite fille malfaisante ! / "Que criança daninha!”. Essa passagem ilustra a problemática relação mãe-filha presente nessa obra, assim como em outros textos de Anne Hébert. Problemática, não porque se trata de uma relação em movimento e que estabelece diferenças de opinião entre o novo e o velho, mas simplesmente por não existir.

Acreditamos que, ao escolher Quelle petite fille malfaisante!, Hébert tenha intencionalmente apresentado uma característica negativa ligada ao sexo feminino: malfaisante (malvada), de modo a remeter às dificuldades das relações entre mães e filhas. Na tradução brasileira, porém, não é explicitado o sexo do bebê, uma vez que Carvalho opta por "criança" como tradução de petite fille (menina), atenuando, a nosso ver, um dos traços feministas da obra. Outra atenuação pode ser verificada na tradução de ma mère por "mamãe", em ma mère et moi / "mamãe e eu". "Mamãe" sugere um sentimento de carinho de Elisabeth para com a mãe, que não se deduz do texto em francês e é incoerente com a relação existente entre as duas.

Após o nascimento da filha, Marie-Louise se fecha para a vida e entrega Elisabeth aos cuidados de suas três irmãs. Como consequência, observa-se a ausência de cumplicidade e de diálogo entre mãe e filha, que se estenderá por toda a vida, como se depreende do fragmento a seguir, relativo ao encontro entre as duas, quando Elisabeth, vítima das agressões do marido, procura ajuda na casa materna:

Je raconte ma vie à Kamouraska. Je pleure. Je sanglote. Je fonds en eau. Je tords ma chevelure. Je me mords les poings.

$[\ldots]$ 
Le visage de ma mère se brouille. Son regard s'égare à nouveau. Va rejoindre très loin en elle-même un songe bizarre où toutes les femmes mariées, après avoir donné naissance à une petite fille, n'ont plus qu'à devenir veuves les plus rapidement possible.

- Dommage que la Petite n'ait pas accouché d'une fille... (K, p. 98).

Conto minha vida em Kamouraska. Choro. Soluço. Dissolvo-me em água. Puxo os cabelos. Mordo as mãos.

[...]

Uma névoa como que cobre o rosto de minha mãe. Seus olhos erram novamente para um ponto distante, vão encontrar muito longe, nela mesma, um sonho bizarro no qual todas as mulheres casadas, após dar à luz um filho, nada mais tem a fazer senão tornarem-se viúvas o mais rapidamente possível.

- Que pena não ter ela dado à luz uma menina ... (TK, p. 93).

Observamos, nesse exemplo, que, em português, há a mudança do sexo do bebê em après avoir donné naissance à une petite fille I “após dar à luz um filho". Nessa passagem, podemos depreender, pelo texto de Hébert, que o nascimento de uma menina (petite fille) é que levaria a mãe à viuvez o mais rápido possível. Reforça essa ideia a fala das tias de Elisabeth que vem a seguir: - Dommage que La Petite n'ait pas accouché d'une fille... / “- Que pena não ter ela dado à luz uma menina...". As tias referem-se ao nascimento de Nicolas, filho oriundo do amor entre Elisabeth e o amante Nelson, ao passo que Marie-Louise recordava o nascimento da filha Elisabeth. Ao optar por "um filho" para tradução de une petite fille, Carvalho novamente camufla uma marca feminista do romance. 


\section{Palavras finais}

Percebe-se, portanto, como foi relevante o papel de Anne Hébert no desencadeamento de reflexões teóricas que resultaram na prática da tradução feminista no Canadá. Ao chamar a atenção de Frank Scott, que traduzira seu poema Le tombeau des rois sem observar a presença do feminino no texto, Hébert suscitou discussões sobre as assimetrias de poder em torno da diferença linguística e sexual que foram e continuam a ser intensamente debatidas no âmbito literário e fora dele. Percebe-se, ainda, como dois outros tradutores, que verteram seu romance Kamouraska (um para o inglês e outro para o português), negligenciaram, à semelhança de Scott, marcas de sua obra que podem ser consideradas feministas.

No entanto, apesar desse importante papel de Hébert e de tantas traduções de sua obra, conforme mencionado no início deste trabalho, observamos que muito pouco foi publicado sobre a tradução de textos hebertianos, sobretudo se consideramos que eles foram vertidos para muitas línguas. Além dos trabalhos mencionados no decorrer deste artigo (HÉBERT; SCOTT, 1970; GODARD, 1984; MEZEI, 1986; FORTIER, 2001; GODARD, 2009), identificamos, durante a realização de nossa pesquisa, somente o volume 3 do Cahiers Anne Hébert (LAHAIE; GODBOUT, 2001), que aborda alguns aspectos instigadores do ato tradutório relacionado à obra desta autora. No contexto brasileiro, encontramos a tese de doutorado intitulada Erros em tradução do francês para o português: do plano linguístico ao plano discursivo (CORRÊA, 1991) e o artigo de Vera de Azambuja Harvey (1988), tradutora de Les fous de Bassan, intitulado: "Tradução e transcrição em Les fous de Bassan de Anne Hébert", que traz um breve testemunho da sua experiência tradutória ${ }^{13}$. Daí nosso interesse em estudar traduções de obras desta escritora, objeto da nossa tese de doutorado Traços feministas em traduções brasileiras de obras de Anne Hébert (PORTO, 2012), de onde foram extraídas as discussões presentes neste trabalho. 


\section{Notas}

1. Informação disponível em: < http://www.usherbrooke.ca/centreanne-hebert/ recherche/ $>$. Acesso em: 21 maio 2013.

2. Sítio do Centro Anne Hébert < http://www.usherbrooke.ca/centreanne-hebert/ > . Acesso em 21 maio 2013.

3. captivité et libération, bien et mal, jour et nuit, passé et présent, vie et mort. Todas as citações redigidas em língua estrangeira foram por nós traduzidas, salvo quando indicadas diferentemente.

4. It was only as our discussions came to an end that we realized that something new had emerged. A practice we could call Canadian feminist translation had come into existence.

5. is an apolitical event, and the translator an innocent conduit.

6. Avides de la source fraternelle du mal en moi; / Ils me couchent et me boivent; / Sept fois, je connais l'étau des os; / Et la main sèche qui cherche le cœur pour le rompre (HÉBERT, 2009, p. 62-63).

7. translation produces knowledge and meaning and not just repetitions.

8. Amor, amor, eu te mordo, te bato, te mato (TK, p. 5).

9. As referências à tradução inglesa de Kamouraska (Cf. HÉBERT, 1973) serão indicadas por T, à tradução brasileira (Cf. HÉBERT, 1972) por TK, ao original 
(Cf. HÉBERT, 1970) por K.

10. "Doutor Nelson, amo-o loucamente a ponto, de desejar transpor com você o limiar de sua infância” (TK, p. 117).

11. "Eu o amarei descontroladamente, loucamente, Doutor Nelson. Por favor, deixe-me ir com você $[\ldots]$ de volta à sua infância".

12. No original: "all those texts that reveal a critical awareness of women's subordinate position and of gender as a problematic category, however this is expressed".

13. Para essa busca, consultamos os sítios de pós-graduação das universidades brasileiras que possuem linhas de pesquisa em literaturas francófonas, como é o caso da Universidade Federal Fluminense e da Universidade Federal do Rio Grande do Sul; também examinamos o portal de pesquisa da CAPES e o portal canadense Theses Canada (dissertações e teses defendidas em universidades canadenses).

\section{Referências}

AGUIAR, O. B. Apresentação: a tradução no Programa de Pós-Graduação em Letras e Linguística da UFG. In: Goiânia: Editora da UFG, 2003. p. 11-21. . Tradução: fragmentos de um diálogo.

ANCRENAT, A. La galerie des ancêtres dans Les fous de Bassan. Cahiers Anne Hébert, n. 1, p. 9-28, 1999.

BISHOP, N. B. Anne Hébert, son æuvre, leurs exils. Bordeaux: Presses Universitaires de Bordeaux, 1993. 
BOISCLAIR, Isabelle; SAINT-MARTIN, Lori. Féminin/Masculin dans l'œuvre d'Anne Hébert. Cahiers Anne Hébert, Sherbrooke-Québec, Éditions Fides, n. 8, 2008.

CORRÊA, A. M. S. Erros em tradução do francês para o português: do plano linguístico ao plano discursivo. 1991. Tese (Doutorado em Letras) - Universidade Federal do Rio de Janeiro, Rio de Janeiro, 1991.

FELSKI, R. Beyond Feminist Aesthetics: Feminist Literature and Social Change. Cambridge: Harvard University Press, 1989.

FORTIER, S. (Non) inscription du féminin dans la traduction anglaise de Kamouraska. In : Cahiers Anne Hébert (Traductions d'Anne Hébert), n. 3, p. 63-76, 2001.

GAUVIN, L.; MIRON, G. Écrivains contemporains du Québec: Anthologie. Montréal: Éditions de l'Hexagone, 1998.

GODARD, B. Translating and sexual difference. Resources for feminist research n.13, p. 13-16, 1984.

. La traduction comme réception: les écrivaines québécoises au Canada anglais. TTR (Traduction, Terminologie, Redaction), v. 15, n. 1, p. 65-98, 2002.

. A tradução: um diálogo entre feministas canadenses e quebequenses. In: NENEVE, M.; MARTINS, G. (Org.). Fronteiras da tradução: cultura, identidade e linguagem. Tradução Ana Maria Felipini Neves e Marco Aurélio Marques. São Paulo: Terceira Margem, 2009. p. 139-151.

HANCIAU, N. et al. Pequena antologia da poesia quebequense. Porto Alegre: Editora da Universidade/UFRGS, 2009.

HARVEY, V. A. de. Tradução e transcriação em: Os gansos selvagens de Bassan de Anne Hébert. Cadernos do CEF (Círculo de Estudos Francófonos - UFF): Le Québec vu du Brésil II. Niterói, n. 03, p. 115-119, 1988. 
HÉBERT, A. Kamouraska. Paris: Seuil, 1970.

. A Máscara da Inocência. Tradução Leônidas Gontijo de Carvalho. São Paulo: Civilização Brasileira, 1972. Título original: Kamouraska.

. Kamouraska. Tradução de Norman Shapiro. New York: Crown Publishers, 1973.

. Les Fous de Bassan. Paris: Seuil, 1982.

HÉBERT, A.; SCOTT, F. Dialogue sur la traduction: à propos du Tombeau des rois. Montréal: HMH, 1970.

IRIGARAY, L. Parler n'est jamais neutre. Paris: Minuit, 1985.

LAHAIE, Christiane; GODBOUT, Patricia. Traductions d'Anne Hébert. Cahiers Anne Hébert, Sherbrooke-Québec, Éditions Fides, n. 3, 2001.

LINTVELT, J. Approche narratologique de la recherche identitaire dans Kamouraska d'Anne Hébert. Revue Canadienne de Littérature Comparée, v. 23, n. 4, p. $1145-1155,1996$.

LOTBINIÈRE-HARWOOD, S. Re-belle et infidèe: La traduction comme pratique de réécriture au féminin. Montréal: Les éditions du remue-ménage, 1991.

MARCHEIX, D. Le mal d'origine: temps et identité dans l'œuvre romanesque d'Anne Hébert. Québec: L’instant même, 2005.

MEZEI, K. The question of gender in translation: examples from Denise Boucher and Anne Hébert. Tessera 3, Canadian Fiction 57, p. 136-141, 1986.

PATERSON, J. M. Anne Hébert : architexture romanesque. Ottawa: Éditions de l’Université d'Ottawa, 1985.

. SAINT-MARTIN, L. Anne Hébert en revue (Collection de Vives Voix). 
Voix et images. Québec: Presses de l’Université du Québec, 2006.

PORTO, Lílian Virgínia. Traços feministas em traduções brasileiras de obras de Anne Hébert. 2012. Tese (Doutorado em Letras e Linguística)- Universidade Federal de Goiás, Goiânia, 2012.

SAINT-MARTIN, L. Malaise et Révolte des femmes dans la littérature québécoise depuis 1945. Québec: Groupe de Recherche multidisciplinaire féministe (GREMF), 1989.

SIMON, S. Gender in translation: cultural identity and the politics of transmission. London: Routledge, 1996.

VON FLOTOW, L. Feminist translation: contexts, practices and theories. Traduction, Terminologie, Redaction -TTR, v.4, n.2, p. 69-84, 1991.

2006.. Feminism in translation: the canadian factor. Quaderns, n. 13, p. 11-20,

. Gender and translation: from identities to pluralities. In: KUHIWCZAK, PIOTR; LITTAU, Karin. A companion to translation studies. Clevedon: Buffalo \& Toronto: Multilingual Matters, 2007. p. 92-105.

WATTEYNE, N. (Org.). Anne Hébert: chronologie et bibliographie des livres, parties de livres, articles et autres travaux consacrés à son œuvre. Montréal: Les Presses de l’Université de Montréal, 2008.

Recebido em: 22/09/2013

Aceito em: 05/01/2014 